\title{
Effects of Cooling Rate on Metallographic Structure and Hardness of Bearing-B Steel
}

\author{
Yisheng Zhao ${ }^{1,2, \text { a }}$ and Xinming Zhang ${ }^{1, b}$ \\ ${ }^{1}$ Central South University, Changsha 410083, PR China \\ ${ }^{2}$ Shenzhen Polytechnic, Shenzhen 518055, PR China \\ ayisheng-zhaoph.d@163.com, bxmzhang_cn@yahoo.cn
}

Keywords: Cooling rate, Metallographic, Hardness, Bearing-B steel

\begin{abstract}
Effects of cooling rate on metallographic and hardness of bearing-B steel were investigated in present research. The results showed it consists of ferrite and pearlite formed in the initial stage of the transformation in the studied bearing-B steels cooled at $0.5^{\circ} \mathrm{C} / \mathrm{s}$. For the higher cooling rate than $10^{\circ} \mathrm{C} / \mathrm{s}$, it consisted of bainite and martensite formed in the initial stage of the transformation. All the results showed that the hardenability of this alloy was sufficient to avoid any elevated temperature transformation which steel sheet was expected to be cooled at rates from 0.5 to $20{ }^{\circ} \mathrm{C} / \mathrm{s}$. The hardness of specimens was rapidly increased for the higher cooling rate than $10^{\circ} \mathrm{C} / \mathrm{s}$. The peak value of the hardness was captured corresponding to the cooling rate of $20^{\circ} \mathrm{C} / \mathrm{s}$ though its invariant then.
\end{abstract}

\section{Introduction}

Boron micro-alloyed steel in automotive components like side impact and bumper beams has extensively developed due to the demand for reduced vehicle weight, improved safety, and crashworthiness qualities. The steel grades including 22MnB5 [1-7], are the common steel grade which produce a fully martensitic microstructure after hot stamping when a watercooled tool is used. Its were applied as hot stamped chassis parts in the automotive industry, like A-pillar, B-pillar, bumper, roof rail, rocker rail and tunnel. Initially, the material exhibits a ferritic-pearlitic microstructure with a tensile strength of about $650 \mathrm{MPa}$. After the hot stamping process, the component finally has fully martensitic microstructure with a total strength of about $1500 \mathrm{MPa}$. The special characteristics of the process steps in the process chain of hot stamping are described in present researches. The special characteristics of the process steps in the process chain of hot stamping are described. Finally, the subsequent processing of the hot stamped parts and the manufacture of the parts with tailored properties are presented. The paper includes both the experimental and numerical investigations in the field of hot stamping. This paper includes the research about effects of cooling rate on metallographic structure and hardness of bearing-B bainite steel. The paper includes both the experimental and numerical investigations in the field of hot stamping.

\section{Experimental details}

An alloy was made in a vacuum induction furnace; the ingot was reheated to $1250^{\circ} \mathrm{C}$ for 1 hour followed by hot rolling into $7 \mathrm{~mm}$ plate. The chemical composition of the resulting alloy is similar to the intended design: Fe-0.24C-0.8Si-1.40Mn -0.04Ti-0.0015B-0.009Ce-0.027Al (wt pct). Cylindrical specimens of length $10 \mathrm{~mm}$ and diameter $3 \mathrm{~mm}$ were subjected to programmed heat treatments in the dilatometer.

Figure 1 presents typical microstructures due to the intermediate decomposition of austenite in the studied bearing-B steels. It can be seen that an intermediate structure with granular morphology forms in the upper temperature range $\left(580-450^{\circ} \mathrm{C}\right)$. In Figure $1(\mathrm{a})$, it consists of ferrite and pearlite formed in the initial stage of the transformation due to the lower cooling rate. In Figure 1(b), it 
consists of bainite formed in the initial stage of the transformation (the light crystals in Figure 1 (b)). The higher the cooling rate, the less carbon is contained in the metal and the higher is the content of the formed bainitic-phase. The process of decomposition of austenite into an intermediate structure with granular morphology stops, and feather-needle structures of upper or lower bainite appeared. In Figure 1(c), it consists of bainite (the light crystals) and martensite (the dark crystals) formed in the stage. Figure 1(d) showed that the hardenability of this alloy is sufficient to avoid any elevated temperature transformation which steel sheet is expected to be cooled at the rates from 0.5 to $20{ }^{\circ} \mathrm{C} / \mathrm{s}$. Judging from Figure 1(d), the alloy should achieve the design strength though it is necessary to estimate the expected elongation. Complete martensite was obtained in the specimens. At the same degree of alloying a higher cooling rate in the metal corresponds to a smaller number of crystals with granular morphology in the structure.
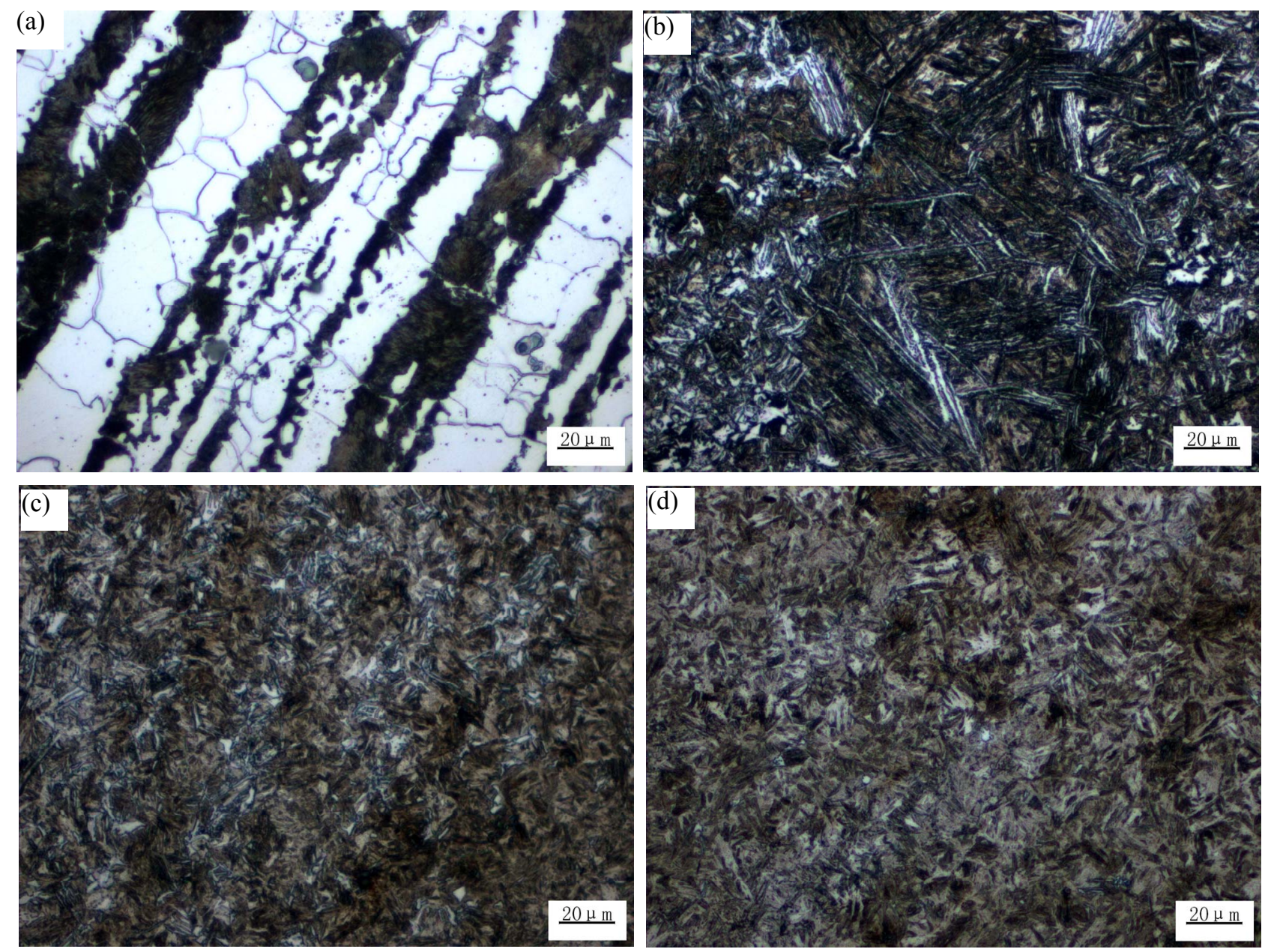

Figure 1 Effects of cooling rate on microstructures of bearing-B steel: (a) $0.5{ }^{\circ} \mathrm{C} / \mathrm{s}$, (b) $5{ }^{\circ} \mathrm{C} / \mathrm{s}$, (c) $8{ }^{\circ} \mathrm{C} / \mathrm{s},(\mathrm{d}) 20^{\circ} \mathrm{C} / \mathrm{s}$

To investigate the material behaviour, hardness tests were carried out where the austenitized specimens were cooled at different rates for a few seconds to preserve the expected microstructure. It has been suggested that the microstructures corresponded to different hardness. The hardness of the microstructure consisted of ferrite and pearlite (corresponding to Figure 1(a)) present a lower hardness which attributed to the incomplete reaction phenomenon of the austenite decomposition. Further increasing the cooling rate, the hardness of the austenitized specimens was degraded. However, the hardness of specimens was rapidly increased for the higher cooling rate than $10^{\circ} \mathrm{C} / \mathrm{s}$. The peak value of the hardness was captured corresponding to the cooling rate of $20^{\circ} \mathrm{C} / \mathrm{s}$ and then it was kept invariant in spite of increasing cooling rate. 


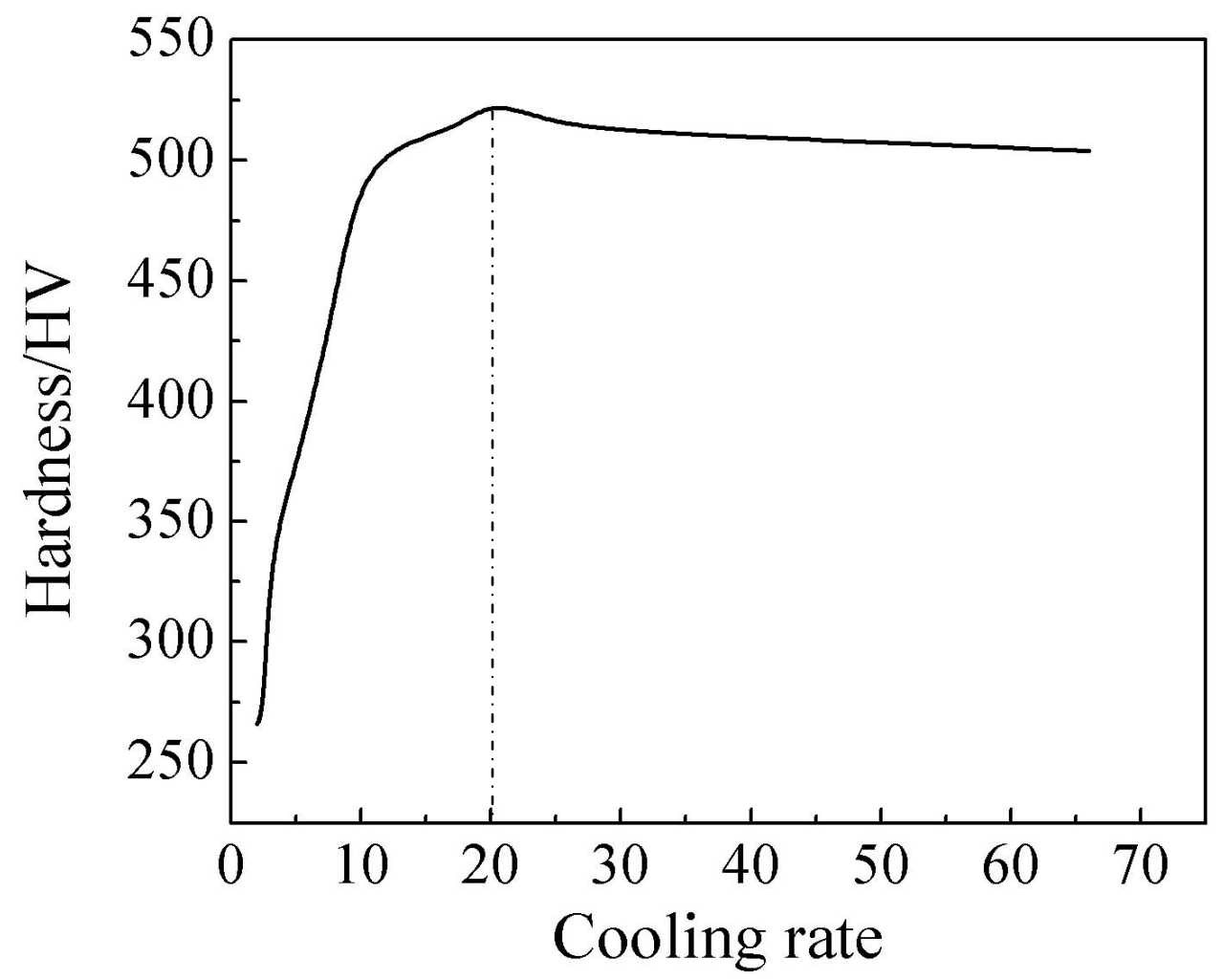

Figure 2 Effects of cooling rate on hardness of bearing-B steel

\section{Summary}

In summary, it consists of ferrite and pearlite formed in the initial stage of the transformation in the studied bearing-B steels cooled at $0.5{ }^{\circ} \mathrm{C} / \mathrm{s}$. For the higher cooling rate than $10^{\circ} \mathrm{C} / \mathrm{s}$, it consists of bainite formed in the initial stage of the transformation. The process of decomposition of austenite into an intermediate structure with granular morphology was inhibited. Feather-needle structures of upper or lower bainite appeared. All the results showed that the hardenability of this alloy is sufficient to avoid any elevated temperature transformation which steel sheet is expected to be cooled at rates from 0.5 to $20{ }^{\circ} \mathrm{C} / \mathrm{s}$. The hardness of specimens was rapidly increased for the higher cooling rate than $10^{\circ} \mathrm{C} / \mathrm{s}$. The peak value of the hardness was captured corresponding to the cooling rate of $20^{\circ} \mathrm{C} / \mathrm{s}$ though its invariant then.

\section{References}

[1] M. Naderi, A. Saeed-Akbari, W. Bleck, Materials Science and Engineering A, Vol. 487 (2008), p 445.

[2] M. Naderi, L. Durrenberger, A. Molinari, W. Bleck, Materials Science and Engineering A, Vol. 478 (2008), p. 130.

[3] M. Merklein, J. Lechler, Journal of Materials Processing Technology, Vol. 177 (2006), p. 452.

[4] A. Turetta, S. Bruschi, A. Ghiotti, Journal of Materials Processing Technology, Vol. 177 (2006), p. 396.

[5] H. Karbasian, A.E. Tekkaya, Journal of Materials Processing Technology, Vol. 210 (2006), p. 2103.

[6] D. W. Fan, R. B. Park, Y. R. Cho, B. C. De Cooman, Steel Research International, Vol. 81 (2010), p. 292.

[7] L. Dosdat, J. Petitjean, T Vietoris, O. Clauzeau, Steel Research International, Vol. 82 (2011), p. 726. 